\title{
Bowen Oranı Enerji Dengesi Yöntemiyle Buğday Su Tüketiminin Belirlenmesi
}

\author{
Deniz Levent KOÇ1 ${ }^{1}$, Rıza KANBER ${ }^{2}$ \\ Çukurova Üniversitesi Ziraat Fakültesi Tarımsal Yapılar ve Sulama Bölümü, Adana \\ ${ }^{1}$ https://orcid.org/0000-0002-4495-3060, ${ }^{2}$ https://orcid.org/0000-0001-7758-8787 \\ 凶: leventk@cukurova.edu.tr
}

\section{ÖZET}

Araştırmada, Çukurova yöresinde doğal yağış koşullarında yetiştirilen buğday bitkisinin gerçek su tüketimi, Bowen oranı enerji dengesi (BREB) ve su bütçesi yöntemleri kullanılarak belirlenmiştir. Buğdayın mevsimlik su tüketimi BREB yöntemiyle $477 \mathrm{~mm}$, su bütçesi yöntemiyle $494 \mathrm{~mm}$ hesaplanmıştır. Sulanan buğday konusunda ise mevsimlik su tüketimi su bütçesi yöntemiyle $708 \mathrm{~mm}$ hesaplanmıştır. Su bütçesi ile BREB yöntemi kullanılarak elde edilen bitki su tüketimi değerleri arasında $\mathrm{R}^{2}=0.83$ olan doğrusal bir ilişki bulunmuştur. Buğday bitkisine ilişkin bitki katsayıları (Kc), FAO-Penman-Monteith (PM) eşitliği kullanılarak hesaplanmıştır. Kc değerleri başlangıç, bitki gelişimi, mevsim ortası ve mevsim sonu dönemleri için, sırasıyla $0.55,0.98,1.47$ ve 0.77 olarak hesaplanmıştır. Denemede dane verimi değerleri susuz ve sulanan konuda sirasıyla 661 ve

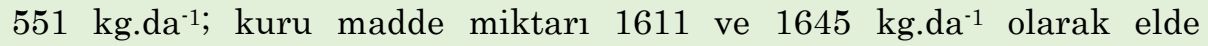
edilmiştir. Su kullanma randımanları ise, kuru madde esasına göre (WUEb) susuz ve sulanan konuda sirasiyla 3.38 ve 3.45 g. $\mathrm{m}^{-2} . \mathrm{mm}^{-1}$; verim esasına göre (WUE $\left.\mathrm{E}_{\mathrm{y}}\right) 1.39$ ve $1.15 \mathrm{~g} \cdot \mathrm{m}^{-2} \cdot \mathrm{mm}^{-1}$ olarak hesaplanmıştır. Hasat indeksi (HI) değerleri ise, susuz ve sulanan konuda, sirasiyla 0.44 ve 0.34 olarak hesaplanmıştır. Yapılan varyans analiz sonuçlarına göre anılan konuların kuru madde miktarı ve dane verimi değerleri arasında istatistiksel anlamda bir fark bulunmamıştır.

\section{Araştırma Makalesi}

\author{
Makale Tarihçesi \\ Geliş Tarihi : 29.07 .2019 \\ Kabul Tarihi : :05.01.2020
}

Anahtar Kelimeler

Bowen oranı

Buğday

Bitki su tüketimi

Bitki katsayısı

\section{Determination of Evapotranspiration for Wheat by Using Bowen Ratio Energy Balance Method}

\section{ABSTRACT}

The actual evapotranspiration of rainfed wheat was determined by using Bowen ratio energy balance and water balance methods under Çukurova region conditions. The seasonal evapotranspiration of rainfed wheat was 477 and $494 \mathrm{~mm}$ for BREB and water budget methods, respectively. The seasonal evapotranspiration of wheat under irrigated conditions was calculated as $708 \mathrm{~mm}$ by using water budget method. A linear correlation $\left(\mathrm{R}^{2}=0.83\right)$ was found between the evapotranspiration obtained by water budget and Bowen Ratio energy balance methods. The single crop coefficients $(\mathrm{Kc})$ for wheat were determined by using the FAO Penman-Monteith equation. The seasonal Kc values were calculated as $0.55,0.98,1.47$ and 0.77 for initial, crop development, mid-season and maturity periods, respectively. The grain yield was 661 and $551 \mathrm{~kg} \cdot \mathrm{da}^{-1}$; the biomass was 1611 and $1645 \mathrm{~kg} \mathrm{da}^{-1}$ under rainfed and irrigated conditions, respectively. The biomass water use efficiency (WUEb) was 3.38 and $3.45 \mathrm{~g} . \mathrm{m}^{-2} \cdot \mathrm{mm}^{-1}$ whereas grain yield water use efficiency $\left(\mathrm{WUE}_{\mathrm{y}}\right.$ ) was 1.39 and 1.15 g.m ${ }^{-2} . \mathrm{mm}^{-1}$ for rainfed and irrigated conditions, respectively. Harvest index (HI) was 0.44 and 0.34 for rainfed and irrigated conditions, respectively. On the basis of the rainfed and irrigated conditions, there were no significant differences between grain yield and biomass values according to the variance analysis.

\section{Research Article}

\section{Article History}

Received : 29.07.2019

Accepted : : 05.01.2020

Keywords
Bowen ratio
Wheat
Evapotranspiration
Crop coefficient

Keywords

Bowen ratio

Wheat

Crop coefficient

To Cite : Koç DL, Kanber R 2020. Bowen Oranı Enerji Dengesi Yöntemiyle Buğday Su Tüketiminin Belirlenmesi. KSÜ Tarım ve Doğa Derg 23(2): 544-553. DOI: 10.18016/ksutarimdoga.vi.597980. 


\section{GİRIŞ}

Doğru sulama programının iki önemli öğesi; suyun ne zaman ve ne miktarda verilmesi gerektiğidir. $\mathrm{Bu}$ kararları verebilmek için tarla koşullarında bitki su tüketimi (evapotranspirasyon) ile ilgili kesin bilgilere gereksinim vardır. Toprak-bitki-atmosfer ortamı içerisinde bulunan ve sulama projelerinin temelini oluşturan bitki su tüketimi gerek tarım gerekse çok amaçlı projelerin planlanması, yapımı ve işletilmesinde vazgeçilmez bir öğedir. Sulama sistemlerinin kapasiteleri, yaz mevsiminde kısa bir dönemde görülen en yüksek tüketim değerini karşılayabilmek için gerekli suyu sağlayacak şekilde planlanır. $\mathrm{Bu}$ yüzden sulama projelerinin doğru planlanması ve işletilmesi, bölge koşullarında yetiştirilen bitkilerin aylık ve daha kısa dönemlere ilişkin bitki su tüketim miktarlarının doğru ölçülmesine bağlıdır (Burman and Pochop, 1994).

Bitki su tüketiminin ölçülmesi için çok sayıda model ve yöntem geliştirilmiştir (Burman and Pochop, 1994). Bu yöntemlerden yaygin olarak kullanılanları su dengesi (lizimetreler, nem azalma), mikrometeorolojik yöntemler (Bowen oranı enerji dengesi, eddy korelasyon) ve fizyolojik yöntemler (bitki taç odacığı, ısı çarpışı/dengesi)'dir (Steduto ve Çetinkökü 1999; Kanber, 1999). Dünya'da ve Türkiye'de bitki su tüketimi daha çok tarla parsellerinde ve lizimetrelerde su bütçesi eşitliği kullanılarak ölçülmektedir. Ancak, tarla parsellerinde anılan eşitliğin kimi öğelerinin ölçülme güçlüğü ve yapılabilecek hatalar, elde edilen sonuçların önemli bir bölümünü tartışılır hale getirmiştir. Diğer yandan en doğru ve en doğrudan yöntem olmakla birlikte, tartılı lizimetrelerin oldukça pahalı ve hareketsiz sistemler olması, bunların bitki su tüketimi çalışmalarında kullanılmalarını kısitlamaktadır (Reicosky et al., 1983; Kanber, 1999). $\mathrm{Bu}$ nedenle geniş alanlarda sürekli ölçüm yapabilen, hareketli, çabuk ve doğru sonuçlar verebilen yöntemlere ihtiyaç duyulmaktadır. Açılklanan niteliklere sahip ve bitki su tüketiminin belirlenmesinde yaygin olarak kullanılan kapalı sistem bitki taç odacıkları (closed-system canopy chamber) yöntemi, küçük parsellerde bitki veya bitki gruplarından oluşan su buharı ve $\mathrm{CO}_{2}$ akı değişimlerini aynı anda ölçebilmektedir. Ancak, odacık yönteminin de en önemli sinırlılığ bitkinin mikroçevresini değiştirmesidir.
Mikrometeoroljik yöntemlerden Bowen oranı enerji dengesi yöntemi (BREB), belli bir sürede günlerce otomatik olarak veri toplamanın kolay olduğu, kuruluş giderlerinin diğer mikrometeorolojik yöntemlere göre daha düşük olduğu ve kısmen basit bir alet olarak sayılabilir (Steduto ve Çetinkökü, 1999). Üstelik, basit ve uygulanabilirliğinden dolayı, BREB yöntemi, çok geniş bir uygulama alanında kullanılabilir (Prueger, 1997). BREB yöntemi enerji akılarının dolaylı ölçümünde sıklıkla kullanılan; net radyasyon, toprak ısı akısı ile iki farklı seviyede sıcaklık ve nem ölçümü temeline dayanan, dayanıklı ve düşük maliyetli bir yöntemdir (Özkoca, 2015). BREB yöntemi, tarla ve bahçe bitkilerinin gerçek evapotranspirasyonunun belirlenmesinin yansıra; ormanlık bölgelerde evapotranspirasyonun belirlenmesi ve hidrolojik döngünün incelenmesinde, göllerde ve bataklıklarda açık su yüzeyi buharlaşmasının hesaplanmasında, eddy korelasyon (EC) yöntemi ile birlikte seralarda evapotranspirasyonun

belirlenmesinde kullanılmaktadır (Abtew, 2005; Dicken et al., 2013; Kumagai et al., 2004; Spittlehouse and Black, 2010, Wang et al., 2014).

$\mathrm{Bu}$ çalışmada, Çukurova koşullarında Bowen oranı enerji dengesi yöntemi (BREB) kullanılarak 10 dekar arazide yağış koşullarında yetiştirilen buğday bitkisinden atmosfere aktarılan su buharı akısının ölçülmesi amaçlanmıştır. Buğday su tüketimi diye tanımlanan akı ölçümleri sonuçları, su bütçesi yöntemiyle karşılaştırılmıştır. Çalışmada, sulanan koşullarda yetiştirilen buğday bitkisinin su tüketimi de belirlenmiştir. Ayrıca, FAO-Penman Monteith (PM) yönteminden yararlanılarak buğday bitkisine ilişkin su tüketim katsayıları (Kc) hesaplanmıştır. Ulaşılan sonuçlar bitkinin farklı büyüme dönemlerine göre irdelenmiştir.

\section{MATERYAL ve METOD}

Deneme, 2003-2004 yıllarında Çukurova koşullarında 10 dekarlık buğday ekili bir alanda yürütülmüştür. Mutlu serisinde yer alan deneme alanı toprakları düz ve düze yakın topografyada olup, yüksek oranda şişme özelliği gösteren kil içerir (Özbek ve ark., 1974). Deneme alanı topraklarının bazı fiziksel ve kimyasal özellikleri Çizelge 1'de verilmiştir (Ünlü, 2000).

Çizelge 1. Deneme alanı topraklarının bazı fiziksel ve kimyasal özellikleri

Table 1. Some physical and chemical properties of experimental soils

\begin{tabular}{lllllllll}
\hline $\begin{array}{l}\text { Katman } \\
\text { Derinliği }(\mathrm{cm})\end{array}$ & $\begin{array}{l}\text { TK } \\
\text { g.g-1 }\end{array}$ & $\begin{array}{l}\mathrm{SN} \\
\text { g.g-1 }\end{array}$ & $\begin{array}{l}\mathrm{As}_{\mathrm{s}} \\
\text { g.cm }^{-3}\end{array}$ & $\mathrm{pH}$ & $\begin{array}{l}\mathrm{EC} \\
\text { dS.m }{ }^{-1}\end{array}$ & $\begin{array}{l}\mathrm{CaCO}_{3} \\
(\%)\end{array}$ & $\begin{array}{l}\text { Özgül } \\
\text { Ağırlık }\end{array}$ & $\begin{array}{l}\text { Bünye } \\
\text { Sinıfı }\end{array}$ \\
\hline $0-30$ & 38.43 & 24.66 & 1.34 & 7.05 & 0.25 & 6.63 & 2.47 & Kil \\
\hline $30-60$ & 38.41 & 24.46 & 1.37 & 7.20 & 0.18 & 8.05 & 2.55 & Kil \\
\hline $60-90$ & 37.31 & 24.31 & 1.39 & 7.05 & 0.19 & 8.29 & 2.60 & Kil \\
\hline $90-120$ & 39.78 & 25.91 & 1.36 & 7.15 & 0.16 & 10.66 & 2.44 & Kil \\
\hline
\end{tabular}


Akdeniz ikliminin hüküm sürdüğü Çukurova'da yazlar sıcak ve kurak, kışlar ılık ve yağışlıdır. Araştırma yöresine ait uzun yıllık ortalama iklim verileri Çizelge 2'de verilmiştir (MGM, 2019).

Araştırmada (23x25) $\mathrm{m}^{2}$ lik bir alanda damla sulama yöntemiyle sulama yapılmış ve "sulanan konu" olarak adlandırılmış; arazinin diğer kısımlarında sulama yapılmamış bitki yağış koşullarında yetiştirilmiştir. $\mathrm{Bu}$ uygulama susuz konu olarak adlandırılmıştır. Denemede, elde edilen veriler eş yapma tekniği ile değerlendirilmiştir. Denemede sulamalar, gravimetrik yöntemle belirlenen $60 \mathrm{~cm}$ derinlikteki toprak nemini, tarla kapasitesine getirecek şekilde damla sulama yöntemiyle yapılmıştır. Buğday çıkışının sağlanması için 22 Kasım ve 2 Aralık 2003 tarihlerinde yağmurlama sulamayla toplam $43 \mathrm{~mm}$ sulama suyu verilmiştir. Diğer sulamalar, damla sulamayla yapılmıştır. İlk sulama ekimden 122 gün sonra (sapa kalkma dönemi) 18 Mart 2004 tarihinde uygulanmıştır.

Çizelge 2. Araştırma yöresindeki uzun ylllık iklim verileri (1928-2019)

Table 2. Long-term climate data in the research area (1928-2019)

\begin{tabular}{lllllll}
\hline İklim Öğeleri & Ocak & Şubat & Mart & Nisan & Mayıs & Haziran \\
\hline Ortalama Sıcaklık, ${ }^{\circ} \mathrm{C}$ & 9.49 & 10.55 & 13.42 & 17.53 & 21.80 & 25.64 \\
\hline Oransal Nem, \% & 66.25 & 66.35 & 65.76 & 67.45 & 66.74 & 66.37 \\
\hline Yağış, mm & 110.72 & 89.61 & 65.12 & 51.38 & 48.41 & 21.96 \\
\hline Buharlaşma (Epan), mm & 44.75 & 52.77 & 83.62 & 111.33 & 158.82 & 201.21 \\
\hline Rüzgar Hızı,m/s & 1.61 & 1.64 & 1.65 & 1.58 & 1.53 & 1.60 \\
\hline Buhar Basıncı Açı̆̆ı, mb & 7.30 & 7.69 & 9.14 & 11.91 & 15.38 & 19.47 \\
\hline İklim Öğeleri & Temmuz & Ağustos & Eylül & Ekim & Kasım & Aralık \\
\hline Ortalama Sıcaklık, ${ }^{\circ} \mathrm{C}$ & 28.21 & 28.68 & 26.10 & 21.68 & 15.85 & 11.17 \\
\hline Oransal Nem, \% & 68.94 & 68.05 & 63.50 & 60.80 & 63.05 & 67.07 \\
\hline Yağış, mm & 10.23 & 9.98 & 19.82 & 43.89 & 71.93 & 124.00 \\
\hline Buharlaşma (Epan), mm & 228.33 & 214.42 & 167.77 & 114.95 & 64.14 & 45.34 \\
\hline Rüzgar Hızı,m/s & 1.69 & 1.57 & 1.40 & 1.24 & 1.23 & 1.45 \\
\hline Buhar Basıncı Açı̆̆ı, mb & 23.63 & 24.17 & 19.10 & 13.81 & 10.15 & 8.12 \\
\hline N:
\end{tabular}

Not: (Kasım-Aralık verileri 2018'e kadar olan ortalama değerleri kapsamaktadır. Buharlaşma verileri 1948'den itibaren ortalama değerleri kapsamaktadır).

Araştırma boyunca toplam $454 \mathrm{~mm}$ sulama suyu verilmiştir. Çıkış suyu hariç, toplamda 5 kez sulama yapılmıştır. Denemede, Adana-99 ekmeklik buğday çeşidi kullanılmıştır. Anılan çeşit kışa ve kuraklı̆̆a orta derecede dayanıklı olup, bitki boyu 95-110 cm'dir. Beyaz sık kılçıklı başak yapısına sahiptir. Yüksek verimli olup sahil bölgelere önerilmektedir (Ay, 2003). Araştırmada, Bowen sisteminde solar radyasyonun ölçümünde bir adet pyranometre, sıcaklık ve nem ölçümlerinde iki adet sıcaklık ve nem algılayıcısı, net radyasyonun ölçümünde bir adet net radyasyon ölçer, rüzgar hızlarının ölçümünde bir adet rüzgar hızı ölçer, toprak ısısının ölçümünde ise, iki adet toprak ısı akısı ölçeri kullanılmıştır. Ayrıca, sistemin enerjisi güneş panelinden (12 volt) sağlanmıştır. Ölçümlerin kaydedilmesinde veri kaydedicisi (data logger) ve ölçümlerin veri kaydedicisinden bilgisayara aktarılmasında ise diz üstü bilgisayar kullanılmıştır.

Buğday bitkisinin gerçek su tüketimi su bütçesi eşitliği (Eşitlik 1) yardımıyla belirlenmiştir (Howell ve ark., 1986).

$\mathrm{ET}_{\mathrm{wB}}=\mathrm{I}+\mathrm{P}+\mathrm{D} \pm \mathrm{R} \pm \Delta \mathrm{S}$

ETwB: Gerçek bitki su tüketimi (mm), I: Sulama suyu miktarı (mm), P: Yağış miktarı (mm), D: Derine süzülme miktarı $(\mathrm{mm})$, R: Yüzey akış miktarı $(\mathrm{mm})$, $\Delta \mathrm{S}$ : Toprak su depolamasındaki değişim miktarı, $\mathrm{mm}$
Arazinin çevresi seddeler ile çevrildiği için yüzey akış kayıp ve kazancı sıfır alınmıştır. Çalışmada $90 \mathrm{~cm}$ için hesaplanan, tarla kapasitesinin üzerindeki nem değerleri derine sızma olarak kabul edilmiştir.

BREB yöntemi buharlaşma yüzeyi üzerine gelen ve kaybolan enerjinin dengesine dayanır (Prueger, 1997). Bowen (1926) tarafından geliştirilen Bowen Oranı Eşitlik 2 kullanılarak hesaplanmıştır.

$B=\frac{H}{L_{e}}$

B: Bowen oranı, H: Duyumsanır isı akısı (W.m-2), Le: Buharlaşma gizli ısı akısı (W.m²)

Toprak, bitki, atmosfer sisteminin enerji dengesi aşağıdaki gibi yazılabilir.

$\mathrm{Rn}=\mathrm{G}+\mathrm{H}+\mathrm{Le}$

Rn: Net radyasyon (W.m-2), G: Toprak ısı akısı (W.m²), H: Duyumsanır ısı akısı (W.m²), Le: Buharlaşma gizli ısı akısı (W.m²)

Enerji dengesi eşitliğindeki terimlerin tümü, doğrudan yüzeye doğru olan akı için pozitif, yüzeyden uzaklaşan akı için negatif olarak işaretlenir. Fakat bu çalışmada yüzeyden uzaklaşan Le akılarının yönleri buharlaşma gizli ısı akılarının net radyasyona bağlı olarak değişimlerinin daha kolay anlaşılabilmesi için pozitif olarak işaretlenmiştir. 
2 ve 3 numaralı eşitliklerden yararlanılarak buharlaşma gizli ısı akısı aşağıdaki şekilde yazılmıştır.

Le $=\frac{R_{n}-G}{1+\beta}$

Çalışmada Bowen oranı aşağıdaki eşitlik aracılığıyla hesaplanmıştır.

$B=\mathrm{Y} \frac{\Delta T}{\Delta e}$

$\Delta \mathrm{T}$ : Sicaklık farkı $\left({ }^{\circ} \mathrm{C}\right), \Delta \mathrm{e}$ : Buhar basıncı farkı $(\mathrm{kPa}), \mathrm{Y}:$ Psikometrik katsayı

Eşitlikteki $\mathrm{G}, \mathrm{Rn}, \Delta \mathrm{e}$ ve $\Delta \mathrm{T}$ Bowen sistemiyle ölçülmüştür. Eşitlik 4 kullanılarak buğday gerçek su tüketimi belirlenmiştir.

Sıcaklık ve nem ölçümleri bitki örtü yüzeyinde iki farklı yükseklikte yapılmıştır. Ölçümlerde sıcaklık ve nem algılayıcıları kullanılmıştır. Algılayıcılar $0.5 \mathrm{~m}$ aralıklarla konumlandırılmış; ilk sıcaklık ve nem ölçer algılayıcısı, bitki örtü yüzeyinden $30 \mathrm{~cm}$; ikincisi ise 80 cm yüksekliğe yerleştirilmiştir (Held ve ark., 1990). Bitki boylarının zaman içerisinde artmasıyla algılayıcıların yükseklikleri değiştirilerek algılayıcılar arasındaki düşey uzaklık korunmuştur.Net radyasyon net radyasyon ölçer kullanılarak belirlenmiştir. Alet bitki örtü yüzeyinden $1 \mathrm{~m}$ yüksekliğe, yere paralel ve algılayıcı başlık güney yönüne gelecek şekilde yerleştirilmiştir (Held ve ark., 1990). Net radyasyon ölçerin algılayıcı noktası üzerine $0.25 \mathrm{~mm}$ kalınlığında polietilen koruyucu, rüzgar ve yağışlardan aletin korunması amacıyla yerleştirilmiştir (Anonim, 1995). Toprak ısı akısının ölçülmesi amacıyla, içerisinde sıcaklık algilayıcıları bulunan 2 adet plaka kullanılmıştır (Anonim, 1991). Isı akısı plakaları toprağın 2-3 cm derinliğine yerleştirilmiştir. Bowen sisteminde ölçümler her saniyede yapılmış ve 5'er dakikalık ortalamalar şeklinde otomatik olarak kaydedilmiştir.

Bitki katsayıları aşağıdaki eşitlik kullanılarak belirlenmiştir (Doorenbos ve Pruitt, 1977).

$\mathrm{Kc}=\frac{E T_{c}}{E T_{o}}$

Kc: Bitki katsayısı, $\mathrm{ET}_{\mathrm{c}}$ : Gerçek bitki su tüketimi $(\mathrm{mm}), \mathrm{ET}_{\mathrm{o}}$ : Kıyas bitki su tüketimi (mm)

Bitki katsayılarını elde etmek için FAO-Penman Monteith (FAO-PM) eşitliği kullanılmıştır.

$$
\mathrm{ET}_{\mathrm{o}}=\frac{0.408 \Delta\left(R_{n}-G\right)+\gamma \frac{900}{T+273} U_{2}\left(e_{s}-e_{a}\right)}{\Delta+\gamma\left(1+0.34 U_{2}\right)}
$$

$\mathrm{T}$ : Ortalama hava sıcaklığ $\breve{1}_{1}\left({ }^{\circ} \mathrm{C}\right), \mathrm{U}_{2}: 2 \mathrm{~m}$ yükseklikte ölçülen rüzgar hızı, (m.s-1), (es-ea): Havanın buhar basıncı açığı, $(\mathrm{kPa}), \Delta$ : Sicaklık-doygun buhar basıncı eğrisinin eğimi $\left(\mathrm{kPa} \cdot{ }^{\circ} \mathrm{C}^{-1}\right)$.

Birim alandan elde edilen dane ağırlığının toprak üstü toplam kuru maddeye oranı olarak tanımlanan hasat indeksi (HI) aşağıdaki eşitlik yardımıyla hesaplanmıştır (Beadle, 1985).

$\mathrm{HI}=\frac{Y}{B K}$

HI: Hasat indeksi, Y: Birim alandan elde edilen dane verimi (g.m $\left.{ }^{-2}\right)$, BK: Toprak üstü kuru madde ağırlığı (biyokütle) (g.m-2)

Su kullanma randımanı Hsiao (1993) tarafindan aşağıdaki şekilde açıklanmıştır.

WUE $=\frac{Y}{I}$

WUE: Su kullanım randımanı, Y: Dane verimi (g.m²), I: Uygulanan sulama suyu miktarı (mm)

Konulara ilişkin toplam su kullanma randımanı evapotranspirasyon değerlerine göre aşağıdaki eşitlik kullanılarak belirlenmiştir.

$\mathrm{WUE}_{\mathrm{ET}}=\frac{\mathrm{Y}}{\mathrm{ET}}$

WUEET: Toplam su kullanma randımanı, ET: Evapotranspirasyon (mm)

Kuru madde su kullanma randımanı ise aşağıdaki eşitlik kullanılarak hesaplanmıştır.

$\mathrm{WUE}_{b}=\frac{Y b}{E T}$

WUE $\mathrm{b}$ : Kuru madde su kullanma randımanı, $\mathrm{Y}_{\mathrm{b}}$ : Kuru madde miktarı (g.m ${ }^{-2}$ )

\section{BULGULAR ve TARTIŞMA}

Su bütçesi yöntemine göre; susuz ve sulanan konuda mevsimlik buğday su tüketimi değerleri sirasıyla 494 $\mathrm{mm}$ ve $708 \mathrm{~mm}$ bulunmuştur. Susuz konuda BREB yöntemine göre ise mevsimlik buğday su tüketimi 477 mm olarak belirlenmiştir. Sezen (1993), Sezen ve Yazar (1996), Çukurova koşullarında yapmış oldukları çalışmalarda su bütçesi yöntemi ile belirlenen buğday su tüketimlerinin farklı sulama düzeylerine bağlı olarak 422 ile $519 \mathrm{~mm}$ arasında değiştiğini belirlemişlerdir. Akpolat (2011), Çukurova koşullarında buğday ile yaptığı çalışmada, BREB yöntemi ile mevsimsel bitki su tüketimini $320 \mathrm{~mm}$ olarak belirlemiştir. BREB metodu gündoğumugünbatımı saatlerinde ve yağışlı zamanlarda hatalı veriler üretebilmektedir ve ölçümlerin doğruluğu uygun verilerin ayıklanma aşamasında kullanılan filtreleme yöntemine direkt bağlıdır (Özkoca, 2015). $\mathrm{Bu}$ iki çalışma arasındaki farklılığa yıllar arasındaki yağış miktarının farklı olması ve verilerin ayıklanmasındaki problemler neden olmuş olabilir. $\mathrm{Bu}$ nedenle uzun yıllık ölçümlerin değerlendirilmesi ve doğrudan ET ölçüm yöntemi olan tartılı lizimetre ile 
karşılaştırılması gerekir. Djaman et al., (2018), Adana gibi yarı kurak bir bölgede (New Mexico) 2002-2014 yılları arasında buğday bitkisi ile yaptıkları bir çalışmada konulara $511 \mathrm{~mm}$ ile $787 \mathrm{~mm}$ arasında sulama suyu uygulamışlardır. Su bütçesi yöntemine göre belirlenen bitki su tüketimleri konulara göre 625 $\mathrm{mm}$ ile $890 \mathrm{~mm}$ arasında değişmiştir. Prueger ve ark., (1997), Adana gibi yarı kurak bir bölgede (Sidney, Avustralya) yaptıkları iki yıllık bir çalışmada, BREB ve lizimetre yöntemlerinden elde edilen mevsimlik bitki su tüketimi değerleri arasında çok az bir fark bulmuşlardır. Fakat araştırmacılar yağışın çok fazla olduğu yılda ise lizimetreden elde edilen mevsimlik bitki su tüketiminin BREB'den elde edilene göre daha fazla olduğunu belirlemişlerdir. Araştırmacılar, yaptıkları bu çalışmada büyük alanlarda BREB yönteminin lizimetrelerle birlikte doğru evapotranspirasyon (ET) tahminleri yaptığ 1 sonucuna varmışlardır. Ünlü ve ark., (2010), Çukurova koşullarında yaptıkları bir çalışmada BREB yöntemi ile tartılı lizimetre yöntemini karşılaştırmışlardır. BREB yöntemi ile lizimetre yöntemi hem günlük ET hem de mevsimsel ET'de birbirine oldukça yakın bir performans göstermiştir. Özkoca (2015), Kırklareli'nde yaptığı bir çalışmada, BREB yöntemi ile buğday bitkisinin gelişme dönemi boyunca su tüketimini 465 $\mathrm{mm}$, EC yöntemi ile $344 \mathrm{~mm}$ olarak belirlemiştir. Sonuçlar, EC'nin BREB'ten \%26 daha düşük ET değeri ürettiğini göstermiştir. Araştırmacı, EC yöntemi ile ölçülen değerlerin BREB'e göre daha düşük olmasının temel sebebinin; yağgışl günler ve rüzgâr hızının düşük olduğu sakin günler ile rüzgâr yönünün hakim doğrultudan gelmediği sistemin doğru ölçüm yapamamasından kaynaklanmış olabileceğini bildirmiştir. Ünlü ve ark., (2014) tarafından Çukurova koşullarında greyfurt bahçelerinde farklı sulama programlarının değerlendirildiği bir çalışmada, BREB yöntemi ile Eddy Korelasyon (EC) yöntemi gerçek evapotranspirasyonun belirlenmesinde yakın sonuçlar vermiştir. BREB yöntemi, ilk kez seralarda Dicken et al.,. (2013) tarafından kullanılmıştır. EC yöntemi ile birlikte İsrail'de bir muz serasında kullanılan BREB yöntemi doğru ve güvenilir sonuçlar vermiştir. Shi et al., (2008) tarafından Çin'de farklı tipte ağaçların olduğu ormanlık bir alanda yapılan çalışmada, MayısEylül gelişme sezonunda, EC ve BREB yöntemleri birbirine yakın ET değerleri üretmiştir.

Araştırmada, Bowen sistemiyle elde edilen enerji dengesi bileşenlerinin mevsim boyunca değişimleri, Şekil 1'de verilmiştir. Net radyasyon miktarı $(\mathrm{Rn})$ ortalama 9 MJ.m ${ }^{-2}$ gün-1 olarak ölçülmüştür. Rn değerleri, Ocak ve Şubat ayında küçük değerlerdeyken; Nisan ve Mayıs aylarında en yüksek değerlere ulaşmıştır. Buharlaşma gizli ısı akı (Le) değerleri net radyasyona benzer bir tavır sergilemiştir.

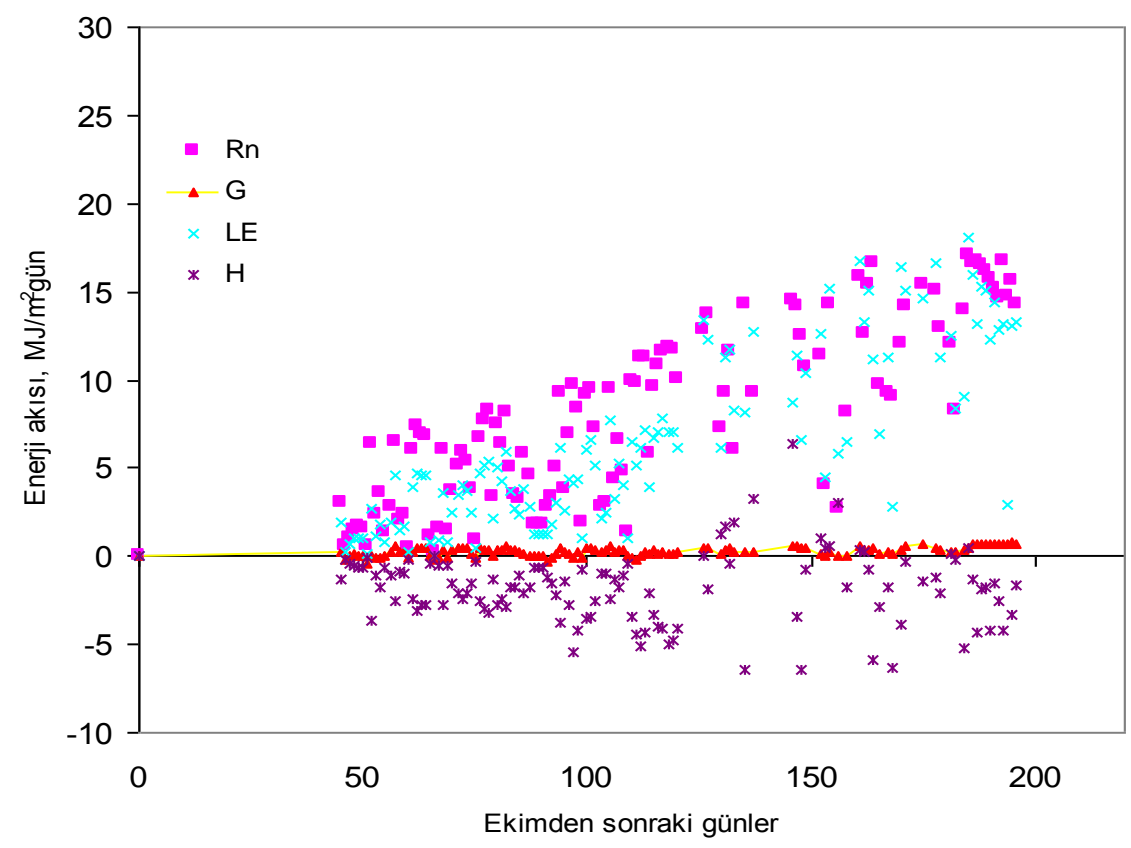

Şekil 1. Enerji dengesi bileşenlerinin büyüme mevsimi boyunca değişimleri

Figure 1. Changes of energy balance components during the growing season

Açık ve kapalı gökyüzü koşullarında enerji dengesi bileşenlerinin değişimi birbirinden çok farklı olmuştur (Şekil 2a, b). Şekil 2a'da net radyasyon akısının (Rn) genelde açık gökyüzü koşullarında gün boyu hiç sapma göstermeden güneşin doğuşuyla birlikte arttığı, öğle saatlerinde pik düzeye ulaştığ 1 ve daha sonra güneşin batışına kadar azalan bir tavır sergilediği görülmektedir. Net radyasyon akısı güneşin doğuşuyla birlikte artmaya başlamış ve öğle saatlerinde pik değere ulaşmış ve güneşin batışına kadar giderek 
azalmıştır. Aynı koşullarda buharlaşma gizli ısı akısı (Le) değerleri net radyasyon akısıyla aynı tavrı göstermiştir. Kapalı gökyüzü koşullarında ise (Şekil 2b) Rn, Le ve duyumsanır ısı akısı (H) değerlerinde sürekli sapmalar olmuş, toprak ısı akı (G) değerleri ise açık gökyüzü koşullarına benzer tavır sergilemiştir.
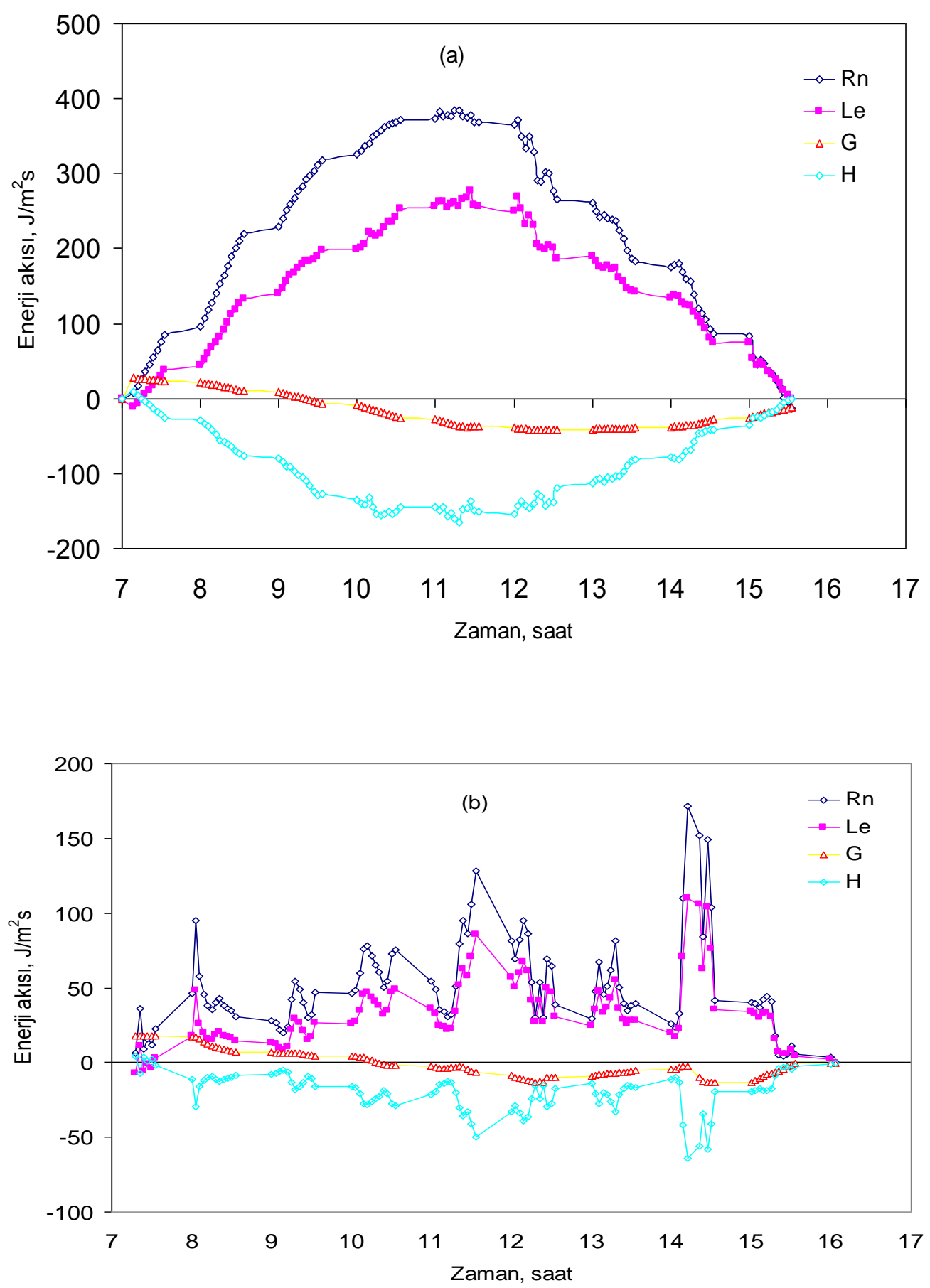

Şekil 2. Enerji dengesi bileşenlerinin değişimi (a) açık ve (b) kapalı gökyüzü koşulları Figure 2. Change of energy balance components (a) open and (b) closed sky conditions

Bitki katsayılarının kestiriminde FAO-PM yöntemi kullanılmıştır. Elde edilen Kc değerleri Çizelge 3’de verilmiştir. Çizelge 3’de görüldüğü gibi, maksimum ve minimum Kc değerleri sirasıyla 1.47 ve 0.55 ; ortalama Kc değeri ise 0.94 olarak hesaplanmıştır. Kang et al.,
(2003), yarı kurak iklime sahip Loess Plateau koşullarında kışlık buğdayla yaptıkları bir çalışmada maksimum ve minimum Kc değerlerini sirasıyla 1.43 ve 0.45 , ortalama $\mathrm{Kc}$ değerini ise, 0.92 olarak hesaplamışlardır. Anılan değerlerle araştırmada elde 
edilen değerler birbirine oldukça yakındır. Irmak et al., (2015) tarafindan yarı kurak bir iklime sahip olan Nebraska'da buğday bitkisi ile yapılan bir çalışmada, Kc değerleri başlangıç dönemi için 0.60, mevsim ortası dönem için 1.30 ve mevsim sonu dönem için 0.30 olarak belirlenmiştir.

Çizelge 3. FAO-PM yöntemine göre bitki katsayılarının mevsimlik değişimi

Table 3. Seasonal changes of single crop coefficients according to FAO-PM method

\begin{tabular}{lcc}
\hline Büyüme Dönemi & $\begin{array}{c}\text { Büyüme Dönemi } \\
\text { Uzunluğu, gün }\end{array}$ & $\mathrm{K}_{\mathrm{c}}$ \\
\hline Başlangıç & 23 & 0.55 \\
\hline Bitki Gelişimi & 25 & 0.98 \\
\hline Mevsim Ortasi & 60 & 1.47 \\
\hline Mevsim Sonu & 68 & 0.77 \\
\hline
\end{tabular}

Konulara göre elde edilen ortalama dane verimi, hasat indeksi ve farklı zamanlarda alınan ortalama kuru madde miktarları Çizelge 4'te verilmiştir. Kuru madde miktarı susuz konuda 1611 kg.da-1; sulanan konuda $1645 \mathrm{~kg} \cdot \mathrm{da}^{-1}$ olarak belirlenmiştir. Yapılan varyans analiz sonuçları bu değerlerin istatistiksel açıdan farksız olduğunu göstermiştir (Çizelge 5). Keklikçi ve ark. (2004), Adana-99 çeşidiyle yaptıkları 2 yıl süren çalışmada kuru madde miktarlarını farklı azot dozlarına bağlı olarak ortalama ilk yıl 1797 kg.da-1 ikinci yll $2023 \mathrm{~kg} \cdot \mathrm{da}^{-1}$ olarak belirlemişlerdir. Elde edilen sonuçlar yukarıda söz edilen çalışma ile yakınlık göstermektedir.

$\mathrm{Bu}$ çalışmada dane verimi susuz ve sulanan konuda sirasıyla $661 \mathrm{~kg} \cdot \mathrm{da}^{-1}, 551 \mathrm{~kg} . \mathrm{da}^{-1}$ olarak bulunmuştur. Yapılan istatistiksel analiz sonuçları bu değerlerin istatistiksel açıdan benzer olduğunu göstermiştir (Çizelge 5). $\mathrm{Bu}$ duruma; buğday yetiştirme mevsiminde düşen yağışların tamamlama sulamadan daha etkili olması ve sıcaklık ve rüzgar gibi iklim etmenlerinin bitki su tüketimini artırarak sulamalardan yararlanmayı olumsuz yönde etkilemesinin neden olduğu düşünülmektedir. Ay (2003), yapmış olduğu iki yıl süren çalışmasında aynı azot dozlarinın ve farkl sulama konularını uygulandığı Adana-99 çeşidi buğdayda, bu çalışmayla benzer şekilde kuru konuda buğday verimini ortalama 707.9 kg.da-1; sulu konuda ortalama 702.5 kg.da-1 olarak belirlemiştir. Keklikçi ve ark., (2004), Adana-99 buğday çeşidiyle yaptıkları bir çalışmada dane veriminin $422-636 \quad \mathrm{~kg} . \mathrm{da}^{-1}$ arasında değiştiğini bulmuşlardır. Yukarıdaki araştırmacıların sonuçları, bu çalışmadan elde edilen sonuçlar ile uyum içerisindedir.

Hasat indeks (HI) değerleri ise; bu çalışmada susuz ve sulanan konuda sirasiyla 0.44 ve 0.34 olarak bulunmuştur. HI arasında istatistiksel anlamda bir fark bulunmamıştır (Çizelge 5). Keklikçi ve ark. (2004), yaptıkları çalışmada Adana-99'da HI değerinin 0.35-0.46 arasında değiştiğini bulmuşlardır. Musick and Porter (1990), yüksek verimli çeşitlerde HI değerlerinin $\quad 0.38-0.60$ arasında değiştiğini bulmuşlardır.

Kuru madde su kullanma randımanları (WUEb $)_{\text {susuz }}$ konuda yaklaşık 3.38 g.m-2 ${ }^{-2} m^{-1}$; sulanan konuda 3.45 g. $\mathrm{m}^{-2} \cdot \mathrm{mm}^{-1}$ olarak hesaplanmıştır. Ulaşılan sonuçlardan da anlaşılacağı gibi sulanan konuda elde edilen kuru madde su kullanma randımanı, susuz konudan daha yüksektir. Susuz konuda verim su kullanma randımanı 1.39 g. $\mathrm{m}^{-2} . \mathrm{mm}^{-1}$; sulanan konuda $1.15 \mathrm{~g} \cdot \mathrm{m}^{-2} \cdot \mathrm{mm}^{-1}$ olarak elde edilmiştir. Sonuçlardan da anlaşılacağı gibi yapılan sulama uygulamaları verimi artırıcı hiçbir etki yapmamıştır.

Benzer iklim koşullarında; Zhang ve ark. (2004), kışlık buğdayda, farklı sulama uygulamaları oluşturdukları çalışmalarında su kullanma randımanlarının 1.11$1.61 \mathrm{~g} . \mathrm{m}^{-2} \cdot \mathrm{mm}^{-1}$ arasında değiştiğini bulmuşlardır. Djaman et al., (2018) tarafindan yarı kurak bir iklimde farklı sulama konularının oluşturulduğu çalışmada, su kullanım randımanları 0.26-1.17 g. $\mathrm{m}^{-2} \cdot \mathrm{mm}^{-1}$ arasında değişmiştir. Sezen (2000) ise, Çukurova koşullarında buğday bitkisiyle yaptığ randımanlarının $\quad 0.66-1.50 \quad$ g. $\mathrm{m}^{-2} \cdot \mathrm{mm}^{-1}$ arasinda değiştiğini bulmuştur.

\section{SONUÇ ve ÖNERILLER}

Araştırma boyunca, sulanan konuya $454 \mathrm{~mm}$ sulama suyu uygulanmış ve $615 \mathrm{~mm}$ yağış kaydedilmiştir. Susuz konuda BREB yöntemine göre mevsimlik buğday su tüketimi $477 \mathrm{~mm}$, su bütçesi yöntemiyle 494 $\mathrm{mm}$ olarak belirlenmiştir. Su bütçesi yöntemiyle elde edilen bitki su tüketim değerleri ile Bowen oranı enerji dengesi yöntemi kullanılarak elde edilen bitki su tüketimi değerleri arasında $\mathrm{R}^{2}=0.83$ olan doğrusal bir ilişki bulunmuştur. Sulanan konuda mevsimlik buğday su tüketimi su bütçesi yöntemiyle $708 \mathrm{~mm}$ olarak saptanmıştır.

Çizelge 4. Konuların ortalama kuru madde miktarı (kg.da-1), dane verimi (kg.da-1) ve hasat indeksi (HI) değerleri Table 4. The average biomass ( $\left.\mathrm{kg} . \mathrm{da}^{-1}\right)$, grain yield ( $\left.\mathrm{kg} . \mathrm{da}-1\right)$ and harvest index values obtained from the treatments

\begin{tabular}{lll}
\hline Kuru Madde Miktarı & Susuz Konu & Sulanan Konu \\
\hline 144.gün (çiçeklenme) & 1231 & 1107 \\
\hline 179.gün (fizyolojik olgunluk) & 1468 & 1416 \\
\hline 190.gün (fizyolojik olgunluk) & 1611 & 1644 \\
\hline Dane Verimi & 661 & 551 \\
\hline Hasat İndeksi & 0.44 & 0.34 \\
\hline
\end{tabular}


Çizelge 5. Ölçülen parametrelerin varyans analizi

Table 5. Analysis of variance for the measured parameters

Kuru Madde Miktarı İçin Yapılan Analiz Tablosu

\begin{tabular}{|c|c|c|c|c|c|c|}
\hline & $\mathrm{n}$ & $\bar{d}$ & $S_{\bar{d}}$ & thesap & $t_{\text {cetvel }}(\mathrm{p} \leq 0.05)$ & $\mathrm{t}_{\text {cetvel }}(\mathrm{p} \leq 0.01)$ \\
\hline 144.gün (çiçeklenme) & 5 & 124 & 83.29 & 1.488 & $2.766 \mathrm{~ns}$ & $4.604 \mathrm{~ns}$ \\
\hline 179.gün (fizyolojik olgunluk) & 4 & 51.75 & 204.55 & 0.25 & $3.182 \mathrm{~ns}$ & $5.841 \mathrm{~ns}$ \\
\hline 190.gün (fizyolojik olgunluk) & 5 & 33 & 168.75 & 0.20 & $2.776 \mathrm{~ns}$ & $4.604 \mathrm{~ns}$ \\
\hline \multicolumn{7}{|c|}{ Dane Verimi İçin Yapılan Analiz Tablosu } \\
\hline & $\mathrm{n}$ & $\bar{d}$ & $S_{\bar{d}}$ & thesap & $\mathrm{t}_{\text {cetvel }}(\mathrm{p} \leq 0.05)$ & $\mathrm{t}_{\text {cetvel }}(\mathrm{p} \leq 0.01)$ \\
\hline 190.gün (fizyolojik olgunluk) & 5 & 110 & 52.68 & 2.09 & $2.776 \mathrm{~ns}$ & $4.604 \mathrm{~ns}$ \\
\hline \multicolumn{7}{|c|}{ Hasat İndeksi (HI) İçin Yapılan Analiz Tablosu } \\
\hline & $\mathrm{n}$ & $\bar{d}$ & $S_{\bar{d}}$ & thesap & $t_{\text {cetvel }}(p \leq 0.05)$ & $t_{\text {cetvel }}(p \leq 0.01)$ \\
\hline 190.gün (fizyolojik olgunluk) & 5 & 0.10 & 0.06 & 1.66 & $2.776 \mathrm{~ns}$ & $4.604 \mathrm{~ns}$ \\
\hline
\end{tabular}

Not: *istatistiksel olarak $\mathrm{p} \leq 0.05$ düzeyinde önemli, $* *$ istatistiksel olarak $\mathrm{p} \leq 0.01$ düzeyinde önemli, ns: önemsiz, n: tekerrür sayısı, $\mathrm{S}_{\mathrm{d}}$ : farkların sapması, $\bar{d}:$ farkların ortalaması, thesap $=\left(\bar{d} / \mathrm{S}_{\mathrm{d}}\right)$

Enerji dengesi bilesenlerinden net radyasyon miktarı (Rn) ortalama 9 MJ.m²gün-1 olarak ölçülmüştür. Rn değerleri, Ocak ve Şubat ayında küçük değerlerdeyken; Nisan ve Mayıs aylarında oldukça yüksek değerlere ulaşmıştır. Buharlaşma gizli ısı akı (Le) değerleri net radyasyona benzer bir tavır sergilemiştir. Net radyasyon akısı $(\mathrm{Rn})$ genelde açık gökyüzü koşullarında gün boyu hiç sapma göstermeden güneşin doğuşuyla birlikte artmış, öğle saatlerinde pik düzeye ulaşmış ve güneşin batışına kadar azalan bir tavır sergilemiştir. Aynı koşullarda buharlaşma gizli ısı akısı (Le) değerleri net radyasyon akısıyla aynı tavrı göstermiştir. Kapalı gökyüzü koşullarında ise, Rn, Le, ve H (duyumsanır ısı akısı) değerlerinde sürekli sapmalar olmuş, toprak ısı akı değerleri (G) ise açık gökyüzü koşullarına benzer tavır sergilemiştir.

FAO-PM yöntemine göre elde edilen Kc değerlerinden; maksimum ve minimum Kc değerleri sirasıyla 1.47 ve 0.55 ; ortalama $\mathrm{Kc}$ değeri ise 0.94 olarak hesaplanmıştır.

Yığışımlı kuru madde miktarı susuz konuda 1611 kg.da-1; sulanan konuda 1645 kg.da $^{-1}$ olarak belirlenmiştir. Dane verimi susuz ve sulanan konuda

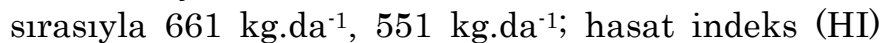
değerleri ise, susuz ve sulanan konuda sirasiyla 0.44 ve 0.34 olarak belirlenmiştir. Varyans analiz sonuçlarına göre konuların dane verimi ve kuru madde miktarları arasında istatistiksel anlamda bir fark bulunmamıştır (Çizelge 5).

Kuru madde su kullanma randımanları susuz konuda yaklaşık 3.38 g.m. ${ }^{-2} \cdot \mathrm{mm}^{-1}$; sulanan konuda 3.45 g.m ${ }^{-}$ ${ }^{2} . \mathrm{mm}^{-1}$ olarak hesaplanmıstır. Susuz konuda verim su kullanma randımanı 1.39 g.m $\mathrm{m}^{-2} . \mathrm{mm}^{-1}$; sulanan konuda 1.15 g.m ${ }^{-2} . \mathrm{mm}^{-1}$ olarak elde edilmiştir.

Bitki su tüketimi çalışmalarında kullanılan su bütçesi yönteminde, derine sızma kayıplarının ölçülmesinde güçlükler yaşanmaktadır. Tartılı lizimetreler sabit ve pahalı sistemlerdir fakat en doğru ET ölçümünü yaparlar. BREB yönteminin adveksiyon koşullarında ve de yağışlı durumlarda çok farklı sonuçlar verdiği bilinmektedir (Prueger, 1997). Bu yüzden, BREB yönteminin lizimetre yöntemiyle birlikte kullanılarak test edilmesi gerekir. Böylece, hangi bölgelerde, hangi bitkilerle güvenle kullanılabileceği söylenebilir. Cukurova kosullarinda BREB ve lizimetre yöntemlerinin karşılaştırıldı ğı çalışmalar (Ünlü ve ark., 2010; Akpolat, 2011), BREB yönteminin hem günlük ET hem de mevsimsel ET'nin belirlenmesinde oldukça doğru sonuçlar verdiğini göstermiştir. Bu bağlamda, BREB yönteminin günlerce otomatik veri toplayabilmesi, diğer mikrometeorolojik yöntemlere göre kuruluş giderlerinin az olması ayrıca daha basit bir yöntem olması nedeniyle Çukurova koşullarında tarla bitkilerinde su tüketimi çalışmalarında kullanılabileceği söylenebilir. Ayrıca, bu yöntemle ölçülen veriler kullanılarak sulama programlarının ve doğru sulama uygulamalarının yapilması mümkündür.

\section{TEŞEKKÜR}

$\mathrm{Bu}$ makale, 2003-2004 yıllarında Çukurova Üniversitesi'nde yapılan bir yüksek lisans tez çalışmasından elde edilen sonuçlar kullanılarak ve bu ylllardan sonraki yeni literatürlerle güncellenerek hazırlanmıştır.

\section{Çıkar Çatışması Beyanı}

Makale yazarları aralarında herhangi bir çıkar çatışması olmadığını beyan ederler.

\section{Araştırmacıların Katkı Oranı Beyan Özeti}

Yazarlar makaleye eşit oranda katkı sağlamış olduklarını beyan ederler.

\section{KAYNAKÇA}

Abtew W 2005. Evapotranspiration in the Everglades: Comparison of Bowen Ratio Measurements and Model Estimations. ASAE Meeting 17-21 July 2005, Florida, USA.

Akpolat A 2011. Mikrometeorolojik ve Lizimetre Yöntemleriyle Belirlenen Buğday Bitki Su 
Tüketimlerinin Karşılaştırılması. Çukurova Üniversitesi Fen Bilimleri Enstitüsü Tarımsal Yapılar ve Sulama Anabilim Dalı Yüksek Lisans Tezi, Adana, 73 sy.

Anonim 1991. Campbell Scientific Bowen Ratio System Instruction Manual (Copyright 1987-2005, Campbell Scientific, Inc.).

Anonim 1995. Campbell Scientific Q-7 Net Radiometer User Guide (Copyright 1991-1996, Campbell Scientific, Inc.).

Ay H 2003. Çukurova Koşullarında Bazı Ekmeklik Buğday Çeşitlerinde Sulama ve Farklı Azot Dozlarının Verim, Verim Unsurları ve Bazı Kalite Özellikleri Üzerine Etkisi. Tarla Bitkileri Anabilim Dalı Doktora Tezi, Adana, 174 sy.

Beadle CL 1985. Plant Growth Analysis (Techniques in Bioproductivitiy and Photosynthesis, Pergamon International Library of Science, Technology, Engineering and Social Studies, UK: Ed. Coombs J, Hall DO, Long SP) 20-25.

Bowen IS 1926. The Ratio of Heat Losses by Conduction and by Evaporation from Any Water Surface. Journal of Physical Review 27:779-787.

Burman RD, Pochop LO 1994. Evaporation, Evapotranspiration and Climatic Data (Development in Atmospheric Science) Elsevier Science Ltd. The Netherlands, 278 p.

Djaman K, O’Neill M, Owen C, Smeal D, West M, Begay D, Allen S, Koudahe K, Irmak S, Lambard K 2018. Long-Term Winter Wheat (Triticum Aestivum L.) Seasonal Irrigation Amount, Evapotranspiration, Yield, and Water Productivity under Semiarid Climate. Agronomy 8(96):1-16.

Dicken, U, Cohen, S, Tanny, J 2013. Examination of the Bowen ratio energy balance technique for evapotranspiration estimates in screenhouses. Biosystems Engineering 114(4): 397-405.

Doorenbos J, Pruitt WO 1977. Crop Water Requirements (Irrigation and Drainage Paper) FAO, Rome, $144 \mathrm{p}$.

Held A, Steduto P, Orgaz F, Matista A, Hsiao TC 1990. Bowen Ratio Energy Balance Tecnique for Estimating Crop Net $\mathrm{CO}_{2}$ Assimilation and Comparison with a Canopy Chamber. Theoretical and Applied Climatology 42:203-213.

Howell TA, Musick JT, Tolk JA 1986. Canopy Temperature of Irrigated Winter Wheat. Transactions of the ASAE 29(6):1692-1699.

Hsiao TC 1993. Plant Athmosphere Interactions, Evapotranspiration and Irrigation Scheduling. Course I.C.A.M.A.S. Bari, Italy, 148 p.

Irmak S, Djaman K, Sharma V 2015. Winter Wheat (Triticum Aestivum L.) Evapotranspiration and Single and Basal Crop Coefficients. Transactions of the ASABE 58(4):1047-1067.

Kanber R 1999. Sulama Ders Kitabı. 2. Baskı, Çukurova Üniversitesi Ziraat Fakültesi Yayınları, Adana, 530 sy.
Kang S, Gu B, Taisheng D, Zhang J 2003. Crop Coefficient and Ratio of Transpiration to Evapotranspiration of Winter Wheat and Maize in a Semi-Humid Region. Agric.ultural Water Management 59(3):239-254.

Keklikçi Z, Barut H, Semercioğlu T 2004. Çukurova Bölgesinde Yaygin Olarak Yetiştirilen Bazı Ekmeklik Buğday Çeşitlerinde Fosfor İhtiyacının Belirlenmesi. Eco-Conference 7-8 February 2002, Novi Sad, Yugoslavia.

Kumagai, T, Saitoh TM, Sato Y, Morooka T, Manfroi OJ, Koichiro K, Masakazu S 2004. Transpiration, Canopy Conductance and The Decoupling Coefficient of a Lowland Mixed Dipterocarp Forest in Sarawak, Borneo: Dry Spell Effects. Journal of Hydrology 287(1-4): 237-251.

MGM, 2019. http://www.mgm.gov.tr/mevbis

Musick JT, Porter KB 1990. Wheat (Irrigation of Agricultural Crops USA: Ed. Stewart BA and Nielsen DR) 597-638.

Özbek H, Dinç U, Kapur S 1974. Çukurova Üniversitesi Yerleşim Sahası Topraklarının Detaylı Etüd ve Haritası. Çukurova Üniversitesi Ziraat Fakültesi Yayınları, Adana, 23(8):149.

Özkoca Y 2015. Mikrometeorolojik Yöntemlerle Bitkilerin Enerji Akılarının Belirlenmesi. Meteoroloji Mühendisliği Anabilim Dalı Atmosfer Bilimleri Programı Yüksek Lisans Tezi, 76 sy.

Prueger JH, Hatfield JL, Aase JK, Pikul JL 1997. Bowen-Ratio Comparisons with Lysimeter Evapotranspiration. Agronomy Journal 89 (5):730736.

Reicosky DC, Sharrat BS, Ljungkull, JE, Baker DG 1983. Comparison of Alfalfa Evapotranspiration Measured by a Weighing Lysimeter and a Portable Chamber. Agricultural Meteorology 28:205-211.

Sezen SM 2000. Çukurova ve Harran Ovası Koşullarında Buğdayda Azot-Su-Verim İlişkilerinin Belirlenmesi ve Ceres-Wheat V3 Modelinin Test Edilmesi. Tarımsal Yapılar ve Sulama Anabilim Dalı Doktora Tezi, 211 sy.

Sezen SM, Yazar A 1996. Çukurova Koşullarında Buğdayda Su-Verim İlişkilerinin Belirlenmesi. Doğa Türk Tarım ve Ormancılık Dergisi 20:41-48.

Sezen MS 1993. Çukurova Koşullarında Buğdayda SuVerim İlişkilerinin Belirlenmesi ve Ceres-Wheat Bitki Büyüme Modelinin Test Edilmesi. Tarımsal Yapılar ve Sulama Anabilim Dalı Yüksek Lisans Tezi, 108 sy.

Shi, T., Guan, D., Wu, J., Wang, A., Jin, C. ve Han, S. (2008). Comparison of Methods for Estimating Evapotranspiration Rate of Dry Forest Canopy: Eddy Covariance, Bowen Ratio Energy Balance, and Penman-Monteith Equation. Journal of Geophysical Research 113:1-15.

Spittlehouse, DL, Black TA 2010. Evaluation of The Bowen Ratio Energy Balance Method for Determining Forest Evapotranspiration. 
Atmosphere-Ocean 2:98-116.

Steduto P, Çetinkökü, Ö 1999. Bitki-Atmosfer İlişkilerine Dayalı Evapotranspirasyon Yöntemleri (Bitki Su Tüketiminin Belirlenmesinde Kullanılan Yöntem Bilimi: İnceleme ve Değerlendirmeler, Ç.Ü. Ziraat Fakültesi, CIHEAM/IAM-B, Adana: Der. Kanber R, Steduto P) 61-84.

Ünlü M, 2000. Çukurova Koşullarında Mikrometeorolojik Yöntemlerle Pamuk Su Tüketiminin ve Bitki Katsayılarının Belirlenmesi. Çukurova Üniversitesi Fen Bilimleri Enstitüsü Tarımsal Yapılar ve Sulama Anabilim Dalı Doktora Tezi, Adana, 106 sy.

Ünlü M, Kanber R, Kapur B 2010. Comparison of Soybean Evapotranspirations Measured by Weighing Lysimeter and Bowen Ratio-Energy Balance Methods. African Journal of Biotechnology 9(30): 4700-4713.
Ünlü M, Kanber R, Koç DL, Özekici B, Kekeç U, Yeşiloğlu T, Ortaş I, Ünlü F, Kapur B, Tekin S, Kathner J, Gebbers R, Zude M, Peeters A, Ben-Gal A 2014. Irrigation Scheduling of Grapefruit Trees in a Mediterranean Environment throughout Evaluation of Plant Water Status and Evapotranspiration. Turkish Journal of Agriculture and Forestry 38: 908-915.

Wang W, Xiao W, Cao C, Gao Z, Hu Z, Shoudong L, Shuanghe S, Linlin W, Qitao X, Jiaping X, Dong Y, Xuhui L 2014. Temporal and Spatial Variations in Radiation and Energy Balance across a Large Freshwater Lake in China. Journal of Hydrology 511:811-824.

Zhang Y, Kendy E, Qiang Y, Changming L, Yanjun S, Hongyong S 2004. Effect of Water Deficit on Evapotranspiration, Crop Yield and Water Use Efficiency in the North China Plain. Agricultural Water Management. 64:107-122. 